\title{
Teaching Play Skills to Visually Impaired Preschool Children: Its Effect on Social Interaction
}

\section{Latife Ozaydin}

Gazi University

\begin{abstract}
The aim of this study is to assess the effects that teaching visually impaired (VI) preschool children play skills has on their abilities to initialize and respond to social interactions with their typically developing (TD) peers in a reverse mainstreaming preschool class. The subjects of the study were three female VI students regularly attending a preschool classroom. Based on their teacher's comments, all children were limited in their ability to initiate and maintain social initiations and in their ability to respond to social interaction initialized by their peers. Play skills were taught to the target students using direct teaching methods through small group arrangements outside the class. The study was conducted using a multiple probe design using probe sessions across subjects in order to determine the impact of play skills taught through direct instruction on the social interactions of children in the class. Visual and non-parametric analyses showed that the play skills taught are effective in increasing the target VI students' abilities to initiate interactions with their peers and in increasing their response behaviors. In addition, the target students not only generalized the interaction behaviors that they had learned to a girl of their own age, but they also retained what they had learned 2 and 3 weeks after the completion of the implementations.
\end{abstract}

Keywords: Social interaction skills $\bullet$ Visually impaired $\bullet$ Preschool children $\bullet$ Play skills $\bullet$ Reverse mainstreaming

* The current study was produced out of project no 45/2009-01 funded within the context of Scientific Researches Projects by Gazi University in coordination with Assist. Prof. Latife Özaydın. This study was presented orally as a paper in the 4th World Conference on Educational Sciences (WCES / 2012) in Barcelona on February 2, 2012.

Assist. Prof. Latife Ozaydin (PhD), Health Services Vocational School, Gazi University, Golbasi, Ankara 06830 Turkey

Research areas: Mainstreaming applications in preschool education; Social skills teaching; Early childhood special education; Early intervention Email: lozaydindagazi.edu.tr 
It is has come to be expected that children with special needs (SN) should be mainstreamed in regular education classes and thereby learn their cognitive, behavioral, and social skills from their typically developing (TD) peers by taking them as models during activities (Guralnick, 1999; McWilliam \& Casey, 2008; Terpstra \& Tamura, 2008). However, since problems experienced in variables both in and outside of the classroom have an impact on mainstreaming education, as long as there is no systematic interventions applied, this period does not meet the necessary expectations to ensure successful mainstreaming (Guralnick, 2010; Macy, Squires, \& Barton, 2009; Odom \& McEvoy, 1990; Wolery \& Wilbers, 1994).

More specifically, the results of studies carried out in this field have shown that children with $\mathrm{SN}$ placed in mainstreaming classes during the preschool period were neither able to initiate interaction with their peers on their own, particularly in unstructured activities such as free-time games (Odom \& Watts, 1991), nor were they able take advantage of educational opportunities (Fabes, Hanish, \& Martin, 2003; McGaha \& Farran, 2001; Odom \& Strain, 1984). Among the problems experienced in mainstreaming classes are SN children's own inabilities and the fact that their peers do not include them, or only include them on a limited level, in their activities because of SN children's not having the necessary communication, game, and/or interaction skills (McWilliam \& Casey, 2008; Odom \& Strain, 1984; Özaydın, Tekin-İftar, \& Kaner, 2008; Strain \& Odom, 1986).

Several researchers have studied social interactions and children with developmental disabilities and their peers (Goldstein, Kaczmarek, Pennington, \& Shafer, 1992; Guralnick, 1997; Guralnick, Neville, Hammond, \& Connor, 2007). There have been fewer studies regarding the social interactions of preschool children who are visually impaired (VI) (Celeste, 2006; D’Allura, 2002; McGaha \& Farran, 2001). Research conducted on children who are VI has revealed a significant delay in cognitive development (Dale \& Sonksen, 2002), social interaction behaviors (Celeste \& Grum, 2010; Crocker \& Orr, 1996), language acquisition (James \& Stojanovik, 2007; Pizzo \& Bruce, 2010), and symbolic play developments (Roger \& Puchalski, 1984) for these children when compared to their TD peers. In addition, it was found that the severity of VI children's developmental regression and disabilites varied depending on the degree of vision loss and the age when visual impairment occurred (Dale \& Sonksen, 2002). As an example, it was emphasized that children who are severely VI not only experience serious retardation in expressive language improvements, other developmental areas are badly affected compared to children with better vision levels (Mukaddes, Kılınçaslan, Küçükyazıcı, Şevketoğlu, \& Tuncer, 2007). What is more is that it was determined that blind children and those who are severely VI exhibited such repetitive behaviors as clapping and weaving hands (Brown, Hobson, Lee, \& Stevenson, 1997; Tröster \& Brambring, 1994). In addition, they exhibited a number of behaviors attributed to children with Autism, such as lacking in understanding and sharing others' feelings (Cass, Sonksen, \& McConachie, 1994; Hobson \& Lee, 2010; Tröster, Brambring, \& Beelmann, 1991). Research results also suggest that the deficits of VI children's play skills may negatively affect their interaction with their peers. The following paragraph will analyze studies examining VI children' play development progress.

Studies on early childhood indicate that preschool children's games are the first environment where they acquire social knowledge and interact with their peers (Fantuzzo et al., 1995). It has been observed that children learn social roles and rules such as sharing, lining up, colloboration, and undertaking roles of listener and speaker during play. Observing children's play activities, Piaget (1970) stated that were the most effective learning environment for children, emphasizing the fact that the foundations of children's symbolic thinking were laid through the symbols that they perceived in the real world during the first stage of their cognitive development, the sensory-motor stage.

Piaget (1970) states that two or three-year-old children firstly use objects based on their real world functions; that, for instance, they drink tea from empty cups, eat from empty plates, and that, afterward, they may use the objects out of their real area of use, like using a stool as a car and pieces of paper as money. However, he also pointed out that symbolic play acquisitions, and thus the symbolic thinking and cognitive development of VI children from birth, might be negatively affected due to the fact that VI children are unable to use their vision in reaching stimulants within the real world (Piaget, 1970). In another study highlighting the disadvantageous situations of VI children regarding their play skills, Fraiberg (1977) stated that in his observations of VI children playing with baby dolls, VI children could not be seen playing with them before their 36th month (as cited in Rogers \& Puchalski, 1984). Contrary to Fraiberg's study, 
Rogers and Puchalski 's studies (1984) suggest that a 30-month-old VI girl was determined to have not only made her baby doll have a bath, but was also seen to have made a shoe have a bath and then dried it as if it had been a baby. Rogers and Puchalski stated that there is a powerful relationship between the symbolic play of VI children and their ability to use the answer, 'No,' as well as their ability to form simple sentences. They also reminded educators of their need to monitor and support these two skills since they are milestones reflecting the cognitive development of VI children. It was determined that the social components of the VI children, as well as their language skills, had also contributed to their development in symbolic play. For instance, VI children aged 5-9 whose social components were as good as their TD peers in symbolic play observed they were successful in role-playing and using the symbolic features of the play materials (Bishop, Hobson, \& Lee, 2005). When research results analyzing the games of VI children are evaluated, a majority of them are seen to make similar suggestions. For instance, they emphasized that such children would always be in need of effective and adult mediated interventions to support their play developments with their peers in inclusive classes (Bishop et al., 2005; Celeste, 2006; Giangreco, Edelman, Luiselli, \& Macfarland, 1997) and that a long-term intervention was required since their TD peers showed a limited tolerance in such cases (Celeste, 2007). Separately, some studies state that children aged 0-2 years should be encouraged to play exploratory type games that support their sensorimotor perceptions and expressive language development (Ferguson \& Buultjens, 1995). Other studies state that structured activities using puppets facilitate such children's ability to generalize the positive behaviors that they have learned to different environments (Gronna, Serna, Kennedy, \& Prater, 1999).

It is known that VI children experience many problems in mainstreaming classes due to their deficiencies in developmental areas and problematic behaviors, as mentioned above. As an example, it was found that VI children's teachers did not have enough knowledge and experience (Özaydın \& Çolak, 2011; Wall, 2002), also teachers became anxious when VI children were placed in their class (Brambring, 2001; Preisler, 1993) since their workload increased (Brambring, 2001; Wall, 2002). In addition that they claimed that it was not suitable for VI children to be placed in preschool classes (Gök \& Erbaş, 2011; Özaydın \& Çolak, 2011; Tait \& Wolfgang, 1984). Apart from the problems shared by teachers, TD peers also expressed their fears of blindness. VI children, on the other hand, were found to have negative opinions about their TD peers, stating that they ignored them or refused to play with them when they were asked (Tait \& Wolfgang, 1984). As such, VI children were unable to maintain interactions with their TD peers even though they had already been initiated (D’Allura, 2002; McGaha \& Farran, 2001). One reason explaining their inability to maintain interactions was that TD students did not receive an adequate response from their VI peers. As a result, VI children's TD peers refused to play with them (Tait \& Wolfgang, 1984) especially when they exhibited repetitive behaviors like clapping their hands or swinging (Brown et al., 1997; Tröster \& Brambring, 1994). Their TD peers did not allow VI children to participate in their play activities, refused to let them into their peer groups, or simply preferred not to make friends with them. Therefore, it was found that VI children, due to their feeling socially isolated, spent much of their time either playing alone or remaining silent (Celeste, 2006; McGaha \& Farran, 2001).

Despite the problems experienced, some of the studies investigating the social interaction behaviors of VI children placed in mainstreaming classes with their peers found that VI children could benefit from these mainstreaming classes (D'Allura, 2002; Erwin, 1993). Other studies, however, found that some VI children were not able to benefit from such classes (Crocker \& Orr, 1996; McGaha \& Farran, 2001). Claiming that VI children could benefit from mainstreaming classes, Erwin (1993) pointed out that when VI children who also had additional disabilities were placed in mainstreaming classes, they spent more time with their peers and did not exhibit problematic behaviors. In another study, D'Allura (2002) found that when the interaction levels of VI children in reverse mainstreaming classes are compared with those in special education classes with their peers, children in mainstreaming classes initiated interaction with their TD peers while those in special education classes initiated interaction with adults. In the same study, it was found that VI children in mainstreaming classes became nearly as successful as their TD peers who after the teachers in the mainstreaming class were taught how to implement the cooperative learning method. The researcher emphasized that since VI children enjoyed playing, discovering, and interacting with their peers just as much as their TD peers did, such kind of opportunities should be provided to children much earlier and that those teachers who were to teach in this field be trained in effective teaching implementations. In one of the studies 
suggesting that VI children cannot benefit from mainstreaming environments adequately, Crocker and Orr (1996) pointed out that VI children were unable to initiate interaction with their TD peers; and instead, simply responded to already initiated interactions. Moreover, McGaha and Farran (2001) found that VI children in mainstreaming classes lacked the ability to initiate interactions compared to their TD peers and were unsuccessful in interactions that had already been initiated.

Considering the studies mentioned above in terms of their methods, it is likely to see that most of them are descriptive studies using observation and interview methods aiming at determining the case (Crocker \& Orr, 1996; D’Allura, 2002; Erwin, 1993; McGaha \& Farran, 2001). Another group of studies in the related literature are those using a "mixed method" of both qualitative and quantitative (development and rating scales) data collection instruments (Celeste, 2006; Celeste \& Grum, 2010). In a sample case study, Celeste (2006) investigated the types of play in which a girl participated in a preschool class, her social interaction behaviors, and her social skills using observations, interviews, and scales of development/ compliance. The researcher collected qualitative data by interviewing her parents, teachers, caregivers, and the peers in her classes. During the course of the study, teachers gave their opinions, pointing out that the subject child mostly played alone, was rarely involved in cooperative play, and preferred interactions with adults over her peers. As for the quantitative data obtained from the development and compliance scales, it was found that while the subject child had either met or surpassed average levels in other developmental areas except for in fine motor skills and that she had scored under her age in every play skill sub-dimension and in personal overcoming skills. In a separate, albeit similar, study, Celeste and Grum (2010) compared the social interaction and play behaviors of a preschool VI child in Slovenia and another child of the same age with the same disability in the USA. It was observed that both subjects lacked social interaction skills and that both had surpassed average level in other developmental areas. The researchers pointed out that these two children's social interaction deficiencies did not result from cultural factors, but resulted from individual features peculiar to their visual impairment. It was therefore emphasized that there exists a need for a qualitative social skill teaching program that is not only independent from cultural features, but that also places an emphasis on individuals and on inciting individualistic development.
The results of the above studies show that VI children's social interaction deficiencies have an impact on their initiating social interaction (McGaha \& Farran, 2001) and are cause for a decrease of interaction in already initiated interactions (D'Allura, 2002). The behaviors in the interpersonal interactions in the literature were explained by Kelly and Thibaut's theory of interdependence (1978) (as cited in Sainato, Goldstein, \& Strain, 1992). The theory of interdependence explains those factors that affect one's ability to initiate, maintain, and end relations during interactions. This theory defends the idea that it is likely to talk about mutually satisfying topics when the gains (rewards) to be obtained are higher than the labor to be spent on the topic (cost). The theoretical base of this study, therefore, is that VI children must learn suitable social skills in order to maintain interaction initiated by $\mathrm{TD}$ children and to reduce the amount of labor that they spend maintaining them. The information concerning the fact that VI children's, like all children, enjoy playing, discovering their environment, and interacting with their peers (D'Allura, 2002), interaction increases in the plays where some accessories, costumes and toys that support their cooperation and involvement in the plays are used (Fewell \& Sandall, 1983; Gronna et al., 1999), and problematic behaviors decreases (Erwin, 1993) put a light on the current study. In addition, preferring a single subject research method, which pays special attention to the individualistic features of subjects, is thought to provide support to the related literature because it provides an opportunity to generalize the play skills that VI children learn and to follow up on whether target children are able to retain what they have learned (Tekin \& Kircaail-Ifftar, 2006).

The purpose of the current study is to determine the effect that the play skills taught to preschool VI subjects in line with their individual features and needs has on their social interaction skills with their peers in the preschool classes where reverse mainstreaming is applied. Answers to the following questions were sought: (i) Do the play skills taught to children work to increase VI children's ability to initiate social interaction and respond to already initiated interactions with their peers in the classroom. (ii) Are VI children able to generalize their abilities to initiate social interaction and respond to already initiated interactions with a peer outside the classroom? and (iii) Are VI children able to maintain their abilities to initiate social interaction and respond to already initiated interactions 2 and 3 weeks after having being successfully taught them? 


\section{Method}

\section{Participants}

The current study was carried out in a preschool classroom of a private educational institution serving VI children in Ankara, Turkey. This was the first time that a reverse mainstreaming application was to be introduced to the classroom during the year that the study was carried out. The class had a teacher trained in preschool education who was accompanied by two trainees. It was learned that almost one month after the opening of the educational term, the teacher had some anxieties with regard to not being able to achieve the interaction between VI children and TD their peers. Following the researcher's observations of the class, it was realized that some of the teacher's anxieties had merit and as a result, three of the female VI students were chosen as target children, in other words, as the subjects of the research. Four criteria were selected as prerequisites for the target children; these being, (a) Having vision loss of $85 \%$ or higher in both eyes, (b) Having limitations in social initiations, maintaining social interactions, and responding to already initialized social interaction, (c) Having the ability to move independently (walking, joining the group, etc.), and $(d)$ Having no hearing impairment.

All three subjects were diagnosed with Bilateral Premature Retinopathy (BPR) immediately after birth. The students also attended a one-hour 1:1 instruction twice a week in line with their Individualized Educational Programs (IEP). It was discovered that although some of the social skills were mandated to be taught according to their IEPs, it seemed as if none of the students had yet received any such instruction. Both their teacher and the school administration were requested not to provide any such instruction during the course of the study. The subjects continued their preschool program between the hours 9:00-17:00 throughout the week, except for the hours during which they participated in their individualized educational program. Apart from the three target students, there were three other children who also had additional disabilities in addition to their visual impairment, such as hydrocephaly, heart problem, and physical disabilities. Written consent forms agreeing to their child's participation in the research were received from the families of all the children in the class were received. Of the TD children, one was male and the other two were females. The researcher was fully experienced in the field of early childhood special education and therefore performed all stages of the study. The reliability data were analyzed by an instructor on child development, who happened to also be the school's vice principal and by a teacher of mentally handicapped individuals who was in the process of completing a Master's Program. Both observers were thoroughly experienced in the functional definitions of social interaction behaviors (the study's dependent variables). Written and verbal statements exemplifying the dependent variables were given to the observers by the researcher. The first observer, as she was at school at the time, monitored all the stages taking place during the research, observing the children's behaviors. However, she did not keep a record of these observations.

Lale was 3 years and 10 months old at the beginning of the study. She had 10\% vision in her right eye and was the youngest student who wear glasses in the class. She could see objects with her right eye and manipulate them with her hand. Lale engaged in symbolic play on her own. She could neither establish communication with her TD or VI peers. Even though she played on her own, she wanted an adult to stay near her during meal times and group activities. When her wish was not fulfilled, she reacted by crying. During the time of the study, she lived with her mother, grandparents, and twin sister. She had attended special education with an emphasis on motor and cognitive skills since she was two years of age. Although her teacher thought that Lale could only communicate with adults, Lale could use her verbal and nonverbal communication skills with her peers during interactions. As she would enter a mainstreaming kindergarten the following year, her mother wanted her to play with her peers and initiate interaction.

Gül was 4 years and 8 months old at the beginning of the research. She could perceive natural light and major acts with her power of sight. Gül engaged in symbolic and imaginative play with dolls and Legos by herself.. She liked listening to audio storybooks in the class, singing children's songs on her own, and communicates with adults. She did not communicate with either her TD or VI peers. She was the only child of the family and had received supportive training on orientation, independent movement skills, and self-care skills since she was two and a half years of age. Her teacher thought that Gül had sufficient communicative skills to initiate interaction with her peers. Since she would enter primary school for visually impaired children the following year, her mother wanted her to initiate communication with her peers and engage in cooperative play with them. 
Menekşe was 4 year and 11 months old at the beginning of the research, the eldest student in the class. Menekșe was diagnosed with a visual deficiency and Mild Mental Retardation. Menekșe did not involve in either the games or routine activities and did not make contact with her peers or adults. She spent much of her play activity time lying on the floor and listening audio storybooks. Although she knew the names of the toys and materials in the class, she rarely played with them in the way with which they were meant to be played. In terms of speaking development, she exhibited characteristics of a child in her one-word period of language development. She could use 25 to 30 words for communication. She could repeat the words with regard to the objects and issues in which she was interested from time to time. Last year, she was only able to attend preschool education for a few months. As she had no self-care skills (eating on his own etc.), her education was suspended. She could participate in activities with adult coaching, but would leave after a short time. Six months before the program, she had started attending individual education to improve her motor, self-care, and language skills. She was the only child of the family and lived with her grandmother. As there was no preschool education class for visually impaired children in the city where her parents lived, she spent most of the year with her grandmother. Her grandmother wanted her to establish contact with her peers, respond already initiated interactions, and engage in play. Her classroom teacher also thought that she could respond to the interactions initiated by her peers and could initiate interaction as time passed by imitating the behaviors of her peers. The features defining the target children are presented in Table 1.

\section{Settings}

The baseline level, implementation, probe, generalization, and maintenance sessions were all realized in a preschool classroom of $4 \times 10 \mathrm{~m}^{2}$ during play activities (09:00-10:30). Three learning centers were arranged within the classroom by the researcher and participants a day before the baseline level of the research started. The researcher described the materials that the target children could not identify by giving them examples. A full list of materials used in the learning centers is included in the following section. In selecting where centers were to be positioned, calmer corners unlikely to be affected by classroom traffic were preferred. As for training sessions, they were realized by the researcher in the $3 \times 8 \mathrm{~m}^{2}$ resting room next to the classroom (09:00-10:30). The resting room was prepared before training sessions by placing cushions and some play materials for the children on the floor.

\section{Materials}

Three learning centers were prepared so that the target children might be able to use the play skills that they learned in the implementation sessions with their peers. Firstly, a child living room was formed for Lale's Guesting play with two cushions, a rug $(40 X 50 \mathrm{~cm})$, a toy tray, and two coffee cups. Secondly, a child kitchen was formed for Gül's Food Preparation play with the toy oven in the class $(20 \mathrm{X} 25 \mathrm{~cm})$, a plastic pan, teapot, a kitchen apron, and oven gloves. Finally, a child room was formed for Menekşe's Child Care play with a bathroom basin $(25 \mathrm{X} 30 \mathrm{~cm})$, a doll, diaper, baby underwear clothes, and wet wipes. The materials and equipment used during training sessions were placed in the learning centers within the classroom during implementation sessions. Every correct behavior of the target children was reinforced by continuously using symbolic and social reinforcers during training sessions. As one type of reinforcer, a number of embossed stickers with animal figures chosen by the children by feeling them were used. Reinforcers were used at the end of the activity during implementation sessions, and only social reinforcers were used by fading the figures in the probe, maintenance, and generalization stages of the study. All sessions were recorded with a camcorder.

\begin{tabular}{|c|c|c|c|c|c|c|}
\hline Subjects* & Gender & Age & $\begin{array}{c}\text { Medical } \\
\text { Diagnosis }\end{array}$ & $\begin{array}{c}\text { Educational } \\
\text { Diagnosis }\end{array}$ & Visual Loss (\%) & $\begin{array}{l}\text { Additional } \\
\text { Impairments }\end{array}$ \\
\hline Lale & Female & 3 years 10 months & $\mathrm{BPR}$ & Blind & 90 & - \\
\hline Gül & Female & 4 years 8 months & BPR & Blind & 85 & - \\
\hline Menekşe & Female & 4 years 11 months & BPR & Blind & 85 & Mild MR \\
\hline
\end{tabular}

Note. ${ }^{\star}$ These are not students' real names. 


\section{Independent Variable}

The independent variable (IV) consisted of the play skills taught to VI subjects. The researcher prepared play skills by taking the teacher's views of the target children and by consulting two preschool teachers working in a neighboring school teaching children of a similar age similar to the target children. These two teachers were asked to observe and document the play activities in which the children in their own classes frequently engaged. The researcher held a meeting with the two preschool teachers and a classroom teacher in which they decided on the type of play activities and play skills to be taught depending on each target child's individual needs. Great attention was paid to the fact that the play activities and skills chosen were not only the most necessary for the target children to learn, but also the basic social skills needed for children attending preschool education institutions to be able to initiate and participate in play activities. The play activities taught to the participants were composed of four basic stages; (i) Paying attention to one's peers ( ${ }^{*}$ calling by name, ${ }^{*}$ asking where oneself is), (ii) Directing one's peer to move closer (directing one's peer to where a sound comes from), (iii) Initiating play activities ( ${ }^{*}$ offering to play, ${ }^{*}$ asking what another is doing, * ${ }^{*}$ haring roles) and (iv) Maintaining play activities (*talking about the roles in the play activity, ${ }^{*}$ changing roles/toys, ${ }^{*}$ replying to questions or expressions, ${ }^{*}$ explaining what oneself is doing and ${ }^{*}$ asking what one's peer is doing) (English, Goldstein, Shafer, \& Kaczmarek, 1997). Lale and Gül were taught 11 sub-social skills considered to comprise fewer than 4 basic play skill stages. Menekşe was taught 4 sub-social skills that will allow her to respond to already initiated interactions (directing one's peer to where a sound comes from, changing roles/toys, replying to questions or expressions, explaining about what she is doing).

\section{Dependent Variable}

The dependent variable was preschool VI children's social interactions with their peers. Behaviors initializing interactions between peers were referred to as social initiations and responses to initialized interactions were referred to as social responses in this study. In many studies investigating social action, it is likely to see skills coded under certain headings based on their features in order to facilitate the recording of data (English, Goldstein, Shafer, \& Kaczmarek, 1997; Goldstein \& Ferrell, 1987; Goldstein \& Wickstrom, 1986; Odom \& Ogawa, 1992; Özaydın et al., 2008). Participants were found to exhibit 2 types of initiating behaviors at each stage of the study. These can be divided into correct initiations and incorrect initiations. Correct initiations were exemplified as; (i) Paying peer attention (for example; ${ }^{*}$ calling one by name, ${ }^{*}$ asking what another is doing, ${ }^{*}$ asking where another is, *looking at the face of one's peer while talking), (ii) Using verbal and non-verbal expressions to initiate interaction with one's peer (for example; ${ }^{*}$ asking a question to obtain information, such as: What did you do?, *asking short questions to obtain confirmation from one's peer: Can I play with this now?, Is it okay if...?, *asking questions requiring one's peer to respond physically: Could you pass the spoon to me?, Do you want to swtich dolls?, ${ }^{*}$ delivering an object/toy into another's hand, saying "Here you are!" "Go ahead!"). Incorrect initiations were exemplified as; (i) Talking with a voice hard to hear, (ii) Touching the face or hair of one's peer without permission, (iii) Initiating interaction with an adult, (iv) Whining (stating that she did not want to play with the peer), (v) Shouting at the peer, and (vi) Throwing an object at the peer.

In addition, it was also found that participants exhibited 2 types of responses at each stage of the study divided into correct responses, on the one hand, and both incorrect responses and the behaviors of incorrect responses occurring within 4-5 seconds of an interaction initiated by one's peer, on the other. Correct responses were exemplified as; (i) Listening to what one's peer says (for example; ${ }^{*}$ ending his speech (keeping quite), *looking at or toward the face of the speaker, ${ }^{*}$ directing oneself to the sound of the speaker, *responding when her name is called (ii) Responding to the behavior of directed statement to her by the peer (for example, *answer the question asked: "I will make cheese pie," * giving short answers to the questions asked by the peer: "Yes," "No," or "Of course," ${ }^{\star} U$ sing expressions eliciting kindness and affection: "Thank you," "That's very nice," *giving an object asked for by one's peer: *delivering an object into the peer's hand or by asking, "Can you take this?" "Here it is!"). Incorrect responses were exemplified as; (i) Bending one's head up or down while the peer is talking, (ii) Not responding to a peer's question, (iii) Not passing the object or toy that the peer asks for, (iv) Responding with a low voice hard to hear, (v) Responding by shouting, and (vi) Responding to an adult. Not responding to an interaction initiated by one's peer within 4-5 seconds was included in the incorrect responses. Error correction was made during training sessions by the researcher both for incorrect initiations and responses. The researcher whispered into target children's ears when necessary in order to perpetuate the interaction and to help them to exhibit a correct behavior by giving verbal and physical clues. 


\section{Research Design}

A multiple probe design using probe sessions across subjects from single subject research models was used to investigate the effects of play skills taught to the VI target children through direct instruction. The study's experimental control was obtained by the first subject's baseline level of observed interaction with her peer during a 10 minute period the increase in the initiating and responding behaviors after the teaching of play skills and not having a significant change in the interaction behaviors of the other two subjects when they were not taught the skills. Following the training stage of the other two target students, an increase in the number of interaction initiations and responses to their peers' request for interaction was witnessed during the implementation stage, as was expected.

\section{Experimental Procedure}

The study included baseline level, training sessions, implementation, probe, and maintenance stages as described below.

Baseline Level: During baseline level, target students were asked to play with their peers. The researcher used the target stimulus "Go ahead, Play together!” without any teaching. Target students' interaction initiation and response behaviors were observed over a 10-minute period after the target stimulus was given. Baseline level data were collected until decisive data were obtained in three successive sessions for each target child.

Training Sessions of the Participants: The researcher conducted training sessions in the resting room next to the classroom using different materials and accessories sharing similar features as those used in the learning centers within the classroom., The researcher taught play skills to the target students using small group (2:2 or 1:2) instruction with the VI and TD children. The direct teaching method was used for the following steps: (i) Defining skills, (ii) Matching each finger with a determined action, (iii) Modeling skills by the researcher, (iv) Setting up the role play, and (v) Providing independent application with feedback (English et al., 1997; McGinnis \& Goldstein, 2003). This process was carried out in the same order with all the target children until $80 \%$ of the play skills taught to the subjects were exhibited correctly. Training sessions were ended when Lale and Gül were able to apply 8 of the 11 behavior and when Menekșe was able to apply 3 of the 4 behaviors. Lale and Gül completed five training sessions while Menekşe completed six. In addition, both the teacher and trainee teachers were informed about the implementation stage, using symbol reinforcers, and fading.

Implementation Stage: After the training sessions ended, first Lale was asked to implement the play skills that they had learned with one of their peers in the classroom. The same was then asked of Gül and finally, of Menekșe. Each subject was reminded during the first session of their implementation stage by matching fingers with acquired play skills. After being asked to begin by being given the command, "Go along, play together!" observers observed each target students' interaction initiation and response behaviors. After the researcher gave the target stimulus, the target children were encouraged by the researcher with expressions like "I'm sure you'll have a good, enjoyable time" and "You can do it!" in the case that they were unable to use the play skills that they had been taught with a peer. During the implementation stage, a total of 6 sessions were conducted with Lale and Gül whereas eight were conducted with Menekșe.

Probe Stage: The first probe stage was arranged immediately following the completion of Lale's implementation stage. A total of 3 probe stages were made for each student. Besides, 3 probe sessions were arranged for each probe stage. Just as they were during their baseline level, the researcher asked the target children to initiate play by giving the target stimulus "Go ahead, Play together!" and data were collected in each probe session. Correct social interactions of both the target children and their peers were reinforced by the researcher and the teacher with such verbal expressions as "Well done!" "Good Idea!" and "Wonderful Job."

Maintenance and Generalization Stages: Maintenance stage was conducted during the $2^{\text {nd }}$ and $3^{\text {rd }}$ weeks following the completion of the third implementation stage with each target children by observing social interactions between the peer and the target children. The researcher asked the target children to play with their peers by giving the target stimulus "Come on, play with your friends!" During maintenance sessions, the correct social interactions between peers and target students were reinforced with verbal expressions like "Welldone!" "Good idea!" and "Great job!"

The ability of target children to generalize what they had learned was measured during generalization sessions with a new peer named Yasemin. Yasemin, the daughter of an attendant working at a special education center, is 4 years and 8 months old. Whether 
the target children were able to generalize the social interaction behaviors that they had learned was tested by observing their ability to apply these behaviors with Yasemin. The generalization sessions were conducted as pretest and posttest. Pretest sessions were taken at the beginning of the implementation stage and posttest sessions were taken at the end of each target student's implementation stage. The researcher and the teacher rewarded both target students and their peers for their positive social interactions by using social reinforcers.

\section{Data Collecting}

The effectiveness and reliability data were collected in the study. Effectiveness data were obtained by collecting the data five days a week in order to measure the effect that target children's play skill had on the study's dependent variables, initiations and responses. For this purpose, recordings were made in all sessions with a camera that focused on the interactions among target children and their peer during free play activities. After the researcher gave target stimulus (e.g. "Come on, play together!”), target children's initiations and responses were recorded using Event Recording. Interaction opportunities initiated by peers were evaluated as opportunities for target children to respond to interaction. It was observed in some of the interactions that although target children did not give incorrect responses, they did not make use of this opportunity. In this context, the percentage of each target child's initiations was obtained by dividing the number of interactions initiated in a correct manner by the total number of interactions initiated in a correct and incorrect manner and then multiplying the resulting number by one hundred. The percentage of responses was obtained in a similar way (Laushey \& Heflin, 2000; Laushey, Heflin, Shippen, Alberto, \& Fredrick, 2009). At least 3 sessions were organized for each target child during both the baseline and probe stages of the research. The decision to finish one stage and to advance to the next was made based on whether data points exhibited an ascending trend or not (Laushey et al., 2009). Six sessions were organized for Lale and Gül during the implementation stage and 8 for Menekşe. The implementation stage were terminated, when an ascending trend was observed in subsequent data points after 3 sessions. The maintenance stage was realized in a single session for each target child 2 and 3 weeks after the last probe session.

In recent years, single-subject studies have been supported by non-parametric analyses so that their visual analysis may be easily interpreted through more objective results (Kratochwill et al., 2010; Laushey et al., 2009; Rakap, 2015). In this study, the percentage of non-overlapping data (PND) was found to support the efficiency of the independent variable. PND was obtained for each subject by drawing a straight line starting from the top most data point of the baseline level toward the implementation stage and then by dividing the data points of the implementation stage resting above this line by the total number of data points. The resulting number was then multiplied by 100 (Kratochwill et al., 2010; Rakap, 2015).

Two styles of reliability data were collected: Interobserver Reliability and Procedural Reliability. Data measuring reliability between the observers were recorded by having the same two observers record $30 \%$ of all the stages using Event Recording. Each observer was asked to evaluate two sessions of each participant's implementation stage and one session from each of the other stages, making a total six sessions recorded for each target child and 18 total recordings. Selected randomly, the recordings were transferred onto CDs and given to both observers to evaluate. They were asked to count target students' initiations (correct or incorrect) and responses (correct or incorrect) using Event Recording and then to send them to the researcher. They were calculated using the following formula: Consensus/Consensus + Disagreement x 100 (Alberto \& Troutman, 2009). The results showed that Lale scored $93 \%$ on average with a distribution between $77 \%$ and $100 \%$, that Gül scored $83 \%$ on average with a distribution between $67 \%$ and $94 \%$, and that Menekşe scored $93 \%$ on average with a distribution between $83 \%$ and $100 \%$ (Laushey et al., 2009).

Procedural reliability, on the other hand, was calculated and checked by the researcher using "The Reliability of the Procedural Data Collection Form" prepared by the researcher in order to determine how well each participant scored in accordance with the procedure plan. Before the researcher initiated the study, she recorded expected behaviors on the form. The school's vice-principal analyzed the procedural reliability data by marking on the form after watching short video recordings that summarized each stage of the study. Finally, to determine procedural reliability, the number of behaviors that the vice-principal recorded on the form was divided by the total number of expected behaviors, with the resulting number then being multiplied by 100 (Tekin \& Kurcaali-İftar, 2006; Tekin İftar, Kurt, \& Çetin, 2011). Procedural reliability for each target child was found to be $100 \%$. 


\section{Findings}

\section{Effectiveness}

The effects of the initiation and response play skills learned by the subjects are given in Figure 1. The baseline, implementation, probe, and maintenance sessions are presented in the graphic, and the percentages each target child's correct initiations and responses observed within 10 minutes are shown in two different series. A visual analysis shows that target children's initiations and the responses increased after learning the play skills. The change in dependent variables occurred during the implementation stage after teaching the play skills, with play skills being the study's independent variables. Based on these data, it has been demonstrated using a multiple probe design across subjects that there is a functional relation between teaching play skills to the target children and their abilities to initiate interactions with and respond to their peers.
In this study, apart from determining the visual analysis of the graphic seen in Figure 1 and the effectiveness of the independent variable, the percentage of PND was found to be able to interpret the results and to provide support for understanding them (Kratochwill et al., 2010; Rakap, 2015). Both Lale and Menekşe's nonoverlapping data for both play skills were calculated to be $100 \%$ whereas Gül's initiations were found to be $100 \%$ and her responses $83 \%$.Target children's correct and incorrect initiations and responses observed during the baseline, implementation, probe, maintenance and generalization stages of the study will be discussed in detail in the succeeding section.

The arithmetic means of correct and incorrect interaction behaviors performed for the dependent variables at each stage of the study are given in Table 2 for Lale, in Table 3 for Gül, and in Table 4 for Menekşe.

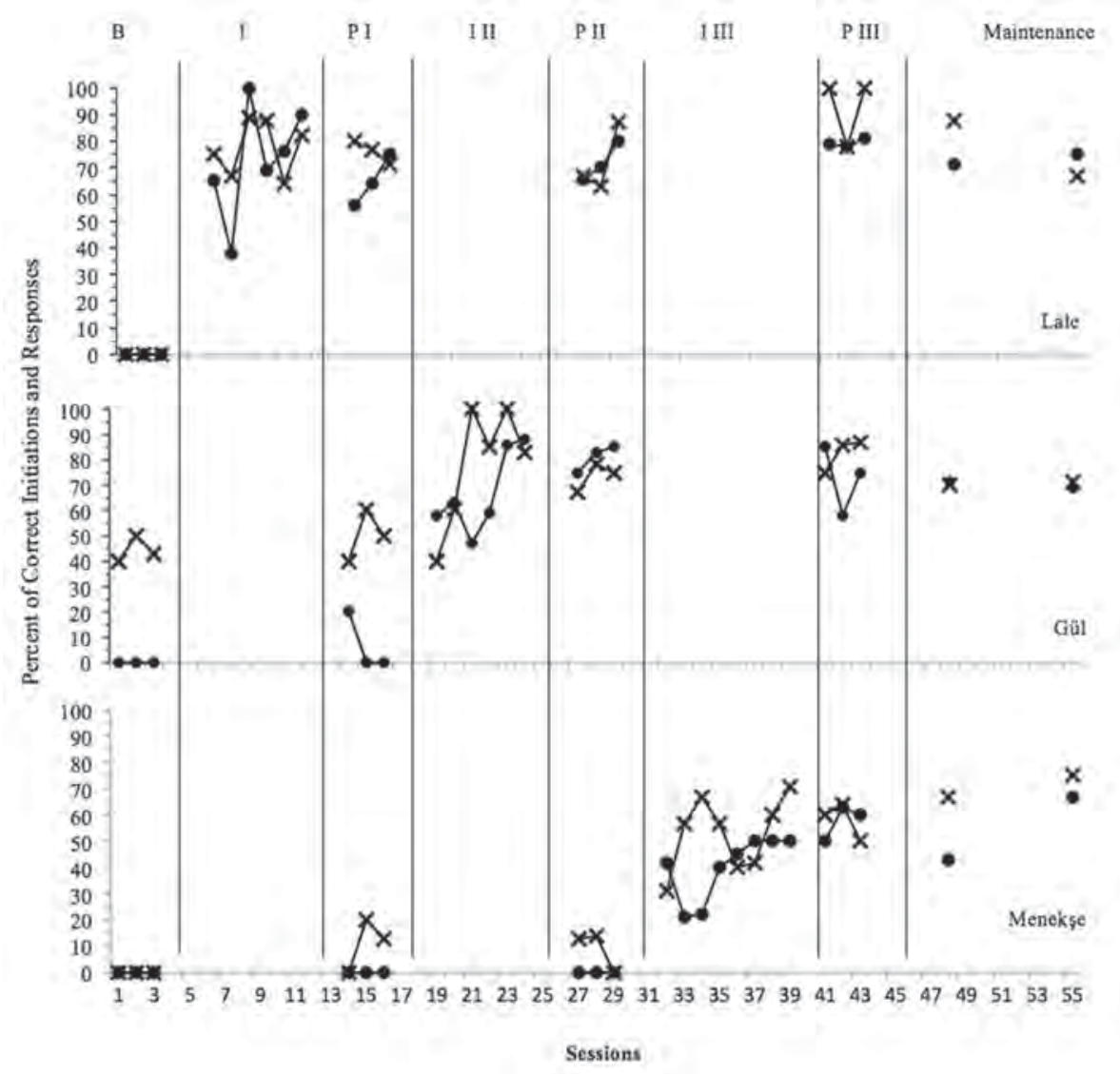

- Initiations X Responses

Figure 1: Percent of target children's correct initiations and responses during Baseline (B), Implementation (I), Probe (P), and Maintenance sessions. 
When Table 2 is examined, it is seen that although Lale did not interact with her peers during baseline sessions, she showed an average of 22 initiations and responses during the implementation stage. During the probe and maintenance stages of the study, not only did Lale's correct usage of initiations and responses continue, the number of incorrect behaviors that she exhibited also decreased. While Lale's average number of initiations with her peers during the 6-session implementation stage totaled 20, 14 were correct and 6 were incorrect for the specific interaction. Lale furthermore gave correct responses to 8 of 10 behaviors initiated by her peers.

\section{Table 2}

Lale's Average Number of the Correct and Incorrect Initiation and the Response Behaviors

\begin{tabular}{lccccccccc}
\hline & \multicolumn{1}{c}{ Lale } \\
\hline & Baseline & $\begin{array}{c}\text { Implemen- } \\
\text { tation }\end{array}$ & Probe & \multicolumn{2}{c}{$\begin{array}{c}\text { Mainte- } \\
\text { nance }\end{array}$} \\
\hline & C & IC & C & IC & C & IC & C & IC \\
\hline Initiation (X) & 0 & 0 & 14 & 6 & 13 & 5 & 7 & 4 \\
Response (X) & 0 & 0 & 8 & 2 & 7 & 2 & 7 & 2 \\
Total & 0 & 0 & 22 & 8 & 20 & 7 & 14 & 6 \\
\hline
\end{tabular}

Note. C: Correct Behaviors; IC: Incorrect Behaviors; X: Average

When Table 3 is examined, it becomes clear that Gül gave more incorrect behaviors to the interaction initiated by her peers when compared with the other target children during baseline sessions. During the implementation stage, she showed a total of 20 correct initiations and responses on average. Gül's correct initiations and responses continued into the maintenance stage, and her incorrect behaviors decreased. Gül's average number of initiations over 6 sessions was found to be 22 in total with 15 of these behaviors being used in correctly. In regards to her responses, Gül gave correct responses to 5 of 6 behaviors initiated by her peer during the implementation stage.

Table 3

Gül's Average Number of the Correct and Incorrect Initiation and the Response Behaviors

\begin{tabular}{lccccccccc}
\hline & Baseline & $\begin{array}{c}\text { Imple- } \\
\text { mentation }\end{array}$ & Probe & $\begin{array}{c}\text { Mainte- } \\
\text { nance }\end{array}$ \\
\hline & $\mathrm{C}$ & IC & C & IC & C & IC & C & IC \\
\hline Initiation (X) & 0 & 0 & 15 & 7 & 8 & 3 & 7 & 3 \\
Response (X) & 2 & 3 & 5 & 1 & 6 & 2 & 12 & 3 \\
Total & 2 & 3 & 20 & 8 & 14 & 5 & 19 & 6 \\
\hline
\end{tabular}

Note. C: Correct Behaviors; IC: Incorrect Behaviors; X: Average

When Table 4 is examined, it is seen that although Menekşe did not interact with her peers during baseline sessions, she showed an average of 10 initiation and response behaviors during the implementation stage. Moreover, although Menekşe's correct number of initiations and responses decreased during the probe stage, they regained a ratio similar to that reached in the implementation stage during the maintenance stage. The total number of incorrect behaviors were also found to decrease over time. Menekşe's average number of initiations over 8 sessions was 8 , with 3 being correct behaviors according to the interaction. It can also be observed that Menekşe gave incorrect responses to 6 of 13 behaviors initiated by her peers during the implementation stage.

\section{Table 4}

Menekşe's Average Number of the Correct and Incorrect Initiation and the Response Behaviors

\begin{tabular}{lcccccccc}
\hline & \multicolumn{8}{c}{ Menekşe } \\
\hline & Baseline & $\begin{array}{c}\text { Imple- } \\
\text { mentation }\end{array}$ & Probe & \multicolumn{2}{c}{$\begin{array}{c}\text { Mainte- } \\
\text { nance }\end{array}$} \\
\hline & C & IC & C & IC & C & IC & C & IC \\
\hline Initiation (X) & 0 & 0 & 3 & 5 & 2 & 1 & 5 & 4 \\
Response (X) & 0 & 0 & 7 & 6 & 2 & 3 & 4 & 3 \\
Total & 0 & 0 & 10 & 11 & 4 & 4 & 9 & 7 \\
\hline
\end{tabular}

Note. C: Correct Behaviors; IC: Incorrect Behaviors; X: Average

\section{Generalization}

It was observed that Lale, Gül and Menekşe were able to generalize the play skills that they had learned to a new-comer, Yasemin. Yasemin was a 4 year and 8 month-old TD child who had rarely attended the class. The generalization sessions were organized in two sessions; one before the training sessions and one after the implementation stage for each of the three target students. It was observed that although none of the three target children interacted with Yasemin before the training sessions, their number of initiations and responses after the implementation stage were similar to those during interactions with their regular classroom peers. In Table 5, target children's total number of correct initiations and responses with Yasemin during pre-test and posttest generalization sessions are given.

\section{Table 5}

Target Children's Average Number of the Correct Initiation and Response Behaviors During Generalization Sessions

\begin{tabular}{lcccc}
\hline \multirow{2}{*}{ Target Child } & \multicolumn{2}{c}{$\begin{array}{c}\text { Initiations } \\
\text { (To Yasemin) }\end{array}$} & \multicolumn{2}{c}{$\begin{array}{c}\text { Responses } \\
\text { (To Yasemin) }\end{array}$} \\
\cline { 2 - 5 } & Pretest & Posttest & Pretest & Posttest \\
\hline Lale & 0 & 12 & 0 & 8 \\
Gül & 0 & 17 & 0 & 7 \\
Menekșe & 0 & 8 & 0 & 4 \\
\hline
\end{tabular}




\section{Maintenance}

It was observed that the three target children continued to use the initiation and response behaviors that they had learned 2 and 3 weeks after the implementation was terminated. In addition, all the subjects used the dependent variables at a rate higher than during their baseline sessions (>50\%).

\section{Discussion}

It is known that since VI children placed in mainstreaming classes cannot observe visual cues and nonverbal feedback, they cannot learn social interaction skills from their TD peers and therefore cannot benefit from peer interaction (Gronna et al., 1999; Roger \& Puchalski, 1984). For this reason, this study aimed to determine the effects of play skills taught to VI children of a special education class in which reverse mainstreaming was applied on initiations and responses with their peers. As for the findings of the study, it was determined that teaching play skills through both visual analysis and non-parametric measurements was effective not only in initiating interaction between VI children and their TD peers, but also in increasing their response behaviors to these interactions. The target children were also found not only to be able to use the skills that they had acquired both 2 and 3 weeks after their last probe sessions had ended, but were able to generalize them by using them correctly with another TD child from outside their regular classroom. In the following paragraph, the questions for which answers were sought are discussed in line with the study's findings and the literature, and suggestions for prospective studies are made.

In this study, a functional relationship was determined between their social interactions and the play skills taught to the VI target children. Of the non-parametric methods, the effectiveness of the PND and the study's independent variable were supported. Thus, the first question of the research was answered positively.

There are studies within the literature that show consistency with the findings of this study's research findings (Bishop et al., 2005; D'Allura, 2002; Erwin, 1993). For instance, D’Allura (2002) stated that just like their TD peers, VI children liked playing, exploring their environment, and interacting with their peers. On the other hand, Erwin (1993) remarked that although VI children are unable to initiate interactions with their peers in play environments, they seemed to spend more time together with their peers and did not exhibit problematic behaviors when they were together. It is known that those play environments providing children an opportunity for peer interactions are not only effective in developing children's imagination, but also provide children with opportunities to gain a wide variety of language and communication skills. Among such skills gained through peer interaction are as the ability to understand and process others' views, the ability to undertake various social roles, and learning both roles listeners and speakers' roles (Guralnick, 2010; Piaget, 1970; Wolery \& Wilbers, 1994). Also in this study, it was observed during baseline sessions that each of the three target children failed to interact with her TD peers and that TD children played among themselves. This changed, however, once the training sessions teaching play skills began. Following the training sessions however, a prominent increase in each of the three target children's initiation and response behaviors was observed. For this reason and since it is through play skills that VI children are provided the opportunity to interact with their peers, the main recommendation of this study is to teach VI children play skills as early as possible.

Piaget (1970) stated that young children aged 2-3 learn to use objects or toys with their real-world functions in the first place and that they later use those objects outside of their real area of use. The subjects in the study were observed to have used all the materials within the classroom correctly in their symbolic sense during the training process. It is expected to see children use the materials provided in their symbolic sense since the learning centers were arranged by a researcher and target children were informed about the purpose of the materials that they could not identify. However, the fact that Lale, in her 3rd implementation session, created a minibus by arranging the chairs in consecutive rows and then sitting in the front as the driver directing two others peers by saying, "You two sit in the back," suggests that she is not only able to use the materials in their true sense, but can even role play an unrelated situation. Lale was also seen using the other classroom materials and toys outside the guesting learning center. Separately, she was also observed using more than one feature of a number of objects; for instance, she consecutively remarked that children were not allowed to drink coffee and that her grandmother made coffee for her grandfather every day. On the other hand, Gül and Menekșe were never seen to use an object apart from those already available in the learning centers or to use materials outside of their real area of use. 
The fact that Lale not only had $10 \%$ vision in her right eye, but that she also wore glasses allowed her the ability to perceive real-world objects thereby providing evidence for visual efficiency's positive effect in the development of symbolic and role play (Piaget, 1970; Roger \& Puchalski, 1984). Lale's other advantage compared to Gül and Menekşe is the fact that she lives in a large family setting consisting of her mother, grandmother, grandfather, and twin-sister with whom she has natural interactions throughout the day. Although all target children had similar VI rates and were diagnosed with BRP, the fact that Lale used her partial visual efficiency in her daily life and her social learning processes within her family circle are considered to have had an effect on her ability to use the 11 play skills taught to her to interact with her peers. Having said this, however, despite all these positive play skills, Lale was often seen asking to play with her teacher or other trainees, saying, "I want to play with the older people."

In the previous section, effects of the study's independent variable on the target children's play skills were scrutinized. In this section, however, the correct and incorrect behaviors of each subject with respect to the dependent variables at the baseline, implementation, probe, and maintenance stages of the study will be discussed in light of Tables 2, 3, and 4 .

When Table 2 is analyzed, despite Lale's abovementioned advantages, it was seen that while she had no interaction with her peers during baseline sessions, she exhibited 14 correct and 6 incorrect interaction initiation behaviors with her peers during the implementation stage following training sessions. Lale's incorrect initiation behaviors were as follows: speaking with a very low tone of voice so as not to let others hear anything, initiating an interaction with an adult, and whining (refusing to play with her peer/requesting to play with an older person). This exemplified Lale's dependency on adults, another dimension of her having a large family considered advantageous in her ability to initiate interactions. When her mother was interviewed, it was learned that Lale had been taken care of by her grandmother due to the severity of her twin-sister's disabilities. Lale was observed wishing to maintain the same dependency that she had developed on her grandmother with her instructor and other adults in the classroom.

Dependency on an adult is a commonly observed case in SN children in mainstreaming classes (Giangreco et al., 1997; Özaydın et al., 2008). However, there are studies in the literature that aim to minimize the amount of teacher support needed to sustain social interactions between SN children and their TD peers and that aim at changing the teacher's role from that of a director to an observer position (Odom \& Watts, 1991). It has also been emphasized that VI children would always be in need of effective adult mediated interventions in order to support play activities with their peers (Bishop et al., 2005; Celeste, 2006). Such interventions are required to be long-term interventions due to the limited tolerance shown by most TD children (Celeste, 2007).

Being an adult-dependent child who had never played with peers in a natural classroom environment, Lale's incorrect initiation behaviors are thought to have been a result not only of her younger age, but also of her home environment and lack of prior peer interaction. The fact that Lale's number of incorrect initiations tended to decrease toward the probe and maintenance stages despite the fact that she preferred to exhibit incorrect initiations since she had never had an experience in playing with a peer before promote that intervention was effective in this case. However, her teacher needs to be educated in using effective intervention systems based on the play activities that reinforce interactions between peers attractive in order to allow Lale the opportunity to want to play with her peers more than adults.

When Table 3 is analyzed, it follows that while Gül initiated no interactions with her peers during the baseline sessions, she did respond, though few in number $(n=5)$, to the interactions initiated by her peers. However, such responses during baseline sessions were mostly seen to be incorrect initiation behaviors, such as bowing her head back or forth and giving no reaction within 4-5 seconds following one of her peers' questions or requests. Behaviors like bowing one's head back and forth, rubbing one's eyes, swinging, and clapping one's hands are known to be repetitive behaviors unique to VI children. It was seen that when TD peers suggested VI children to play with them, they did not tolerate behaviors to which they were not accustomed (Brown et al., 1997; Tait \& Wolfgang, 1984; Tröster \& Brambring, 1994). They were also found not to prefer VI children as friends and although they might have initiated an interaction, it often did not continue since they failed to receive the response that they had expected (D'Allura, 2002; McGaha \& Farran, 2001). Such repetitive behaviors unique to blind and severely VI children were also observed in Menekşe and Gül among the three target children. Gül had experienced $85 \%$ vision loss in both of 
her eyes and was only able to perceive superficial actions, such as when others sit or standup, and apparent shapes, such as checkers, stripes, etc. Along with these restrictions, despite being below her peers in terms of language development and social competencies, she was seen to developed at a level similar to that of her peers in terms of social interaction. When her mother was interviewed, it was discovered that her family had acted more protectively as she was the only child and was usually kept away from TD children. Separately, during this interview, there was the impression that not only had Gül's family moved to Ankara so that she might be able to continue her education in a primary school for the visually impaired children, but that Gül's family was preparing their child to interact in a world of blind children. Although Gül may not currently be using the full potential of her sense of sight in daily life, she still has the opportunity to be successful in mainstreaming education and interact with her peers thanks to her communicative skills and social entrepreneurship. She was seen initiating interactions with her peers, and her incorrect initiation behaviors were observed to have significantly decreased during the probe and maintenance stages following the implementation sessions. Her correct responses also increased during the maintenance stage. The fact that Gül's TD peers enjoyed playing with her with less difficulty after her incorrect response behaviors decreased might have been had an effect on the above-mentioned increase mentioned (Akt. Sainato et al., 1992).

When Table 4 is analyzed, it is seen that while Menekşe had no interactions with her peers during baseline, she exhibited 3 incorrect and 5 correct initiation behaviors with her peers during the implementation stage. In brief, this study may be claimed to have put the main philosophy of mainstreaming applications into practice; that being, "peer to peer" (Guralnick, 1999; Terpstra \& Tamura, 2008). It is known that Menekșe spent a major part of the year with her grandmother since there was no preschool for visually impaired children in the city where her parents lived. She had started school the year before but could not continue due to the difficulties that she experienced in learning self-care skills. For this and similar reasons, it follows that Menekșe's educational process began late.

Regarding Menekşe’s medical report history, no information as to whether or not she had been able to use her visual efficiency in her daily life could be obtained. It was, however, not only stated in her medical diagnosis that she had the same percentage of visual impairment as the other two target children, but also she was restricted expressive language skills. Menekşe was even diagnosed as mild mentally retarded due to her deficiency in expressive language skills in her medical diagnosis report. Although Menekşe's educational process started rather late, and the fact that she not only showed responses to the interactions initiated by her peers, but also initiated interactions with them was found to be quite meaningful in showing the power of play activities and play skills. Menekşe was observed imitating the sound of the water by uttering the expression, 'Splash!' while pouring water over a baby doll in order wash it, and she was even seen drying the doll's hair. Menekşe was seen exhibiting more simple symbolic play behaviors when compared to the other two target children. Although she was the oldest of the three target children, her deficiency in language and symbolic play skills is thought to be because she had experienced less than an adequate number of stimulants in her early years due to her family's protective behaviors, her concerned grandmother, and her having very few experiences with real-world objects or toys.

The research findings emphasize that children's exploratory play in their early years during which they take objects into their mouth, hit them on the floor, or shake them in order to identify them is the precursor for symbolic play activities and expressive language and mental development, pointing out that such opportunities should also be provided for VI children. In this study, Gül and Menekşes grandparents were considered to be incorporated in their educational process in a more systematic way; namely, as actors supporting their grandchildren's education.

Regarding the study's second question, VI children's ability to generalize learned behaviors, the findings of this study show that the participants were able to generalize the skills that they had learned to a female child outside of their regular classroom (Table 5). The fact that the target children were the same age and gender as Yasemin and had similar areas of interest with her are thought to have contributed to their ability to successfully generalize the skills that they had learned. In addition, Yasemin was observed to be quite talented in play guesting, baby care, and imitations, a fact that seemed to affect the study's findings on generalization in a positive way. It was also highlighted in the literature that peers with a sense of responsibility and who were described as social competent individuals acted as facilitators in motivating SN children to generalize the skills that 
they had learned (English et al., 1997; Goldstein et al., 1992; Strain \& Odom, 1986). Even though it was not tested as to whether the target VI children were able to generalize what they had learned to other activities and to other real objects, Lale and Gül were observed using other toys and different learning centers found throughout the classroom.

One of the key findings was the fact that all three target children maintained the skills that they had learned a rate of more than $50 \%$. In the $2^{\text {nd }}$ and $3^{\text {rd }}$ weeks following the end of the last probe stage, target children's interactions with their classroom peers were observed to have continued and the classroom's social atmosphere was observed to be changing. In particular, Lale and Gül were seen setting up play activities with their TD peers consisting of 3-4 people. They were also seen using the entire play area of the classroom and being more courageous in moving around independently. Thus, the play skills taught to them, although not included among the objectives of the study, were observed not only to have increased their social interaction skills, but also to have played a part in developing their motor skills. Considering that the study had started in October and ended in June, it may be said that Lale and Gül had maintained and continued to consistently utilize the behaviors and skills that they had learned during the study.

At this point, a series of factors considered key to the maintenance data of the study should be mentioned. First, informing the teachers on how to use cues and reinforcers for correct targeted behaviors during the implementation stage is thought to have made positive contributions to the maintenance data of this study. Another key factor was the fact that the practices in question were implemented in a natural class environment in which the children had been trained. Separately, both the class's daily activity plan and free-time activities were performed without any problems.

Initial studies aiming to increase social interaction in inclusive classes were implemented outside the students' regular classroom, leading to their findings on generalization and maintenance remaining limited (Odom \& Strain, 1984; Strain \& Odom, 1986). Later studies, however, were conducted in children's natural class environment and in play activities in particular, leading to more vigorous results (English et al., 1997; Goldstein \& Ferrell, 1987; Goldstein \& Wickstrom, 1986; Guralnick, 2010). It is seen that there is a similarity between both these studies and the current study's implementation processes and findings in terms of robustness.
Apart from all these positive findings, we can also touch on this study's limitations. First of all, the fact that only one of their TD peers (Ali) during this study process attended the class regularly and that he had the character traits and areas of interest (he liked cars) unique to his gender (he was male and the target students were all female) are considered to have limited the effectiveness of data. It was observed that Ali was unwilling to continue playing with the target students even though he had initiated the interaction and shifted his attention toward different toys that he was interested in. On the other hand, Ayşe is another TD peer, who although registered in the classroom, failed to attend the class regularly. She was more willing to set up play activities with the target children and provided more feedback to improve their incorrect behaviors. For this reason, it is thought that both TD children's attendance and gender should be taken into consideration as major factors in reverse mainstreaming classes. Apart from their social skills and genders, incentive practices, such as offering a discount in fees, should be performed to ensure the regular attendance of TD peers in reverse mainstreaming classes and schools. When such incentives are provided, a higher number of TD peers can not only be ensured, but such undesired situations as boredom and intimidation, as in Ali's case, can also be prevented by distributing duties among peers.

Another limitation in the study is thought to have been caused by factors related to the institution. Although the classroom in question is a preschool special education class opened for VI children, the absence of a special education teacher in the class, the fact that TD children are a minority despite the implementation of reverse mainstreaming, and the absence of an assistant teacher or paraprofessional to provide cues when required and to use reinforcers for correct behaviors through monitoring the peer interactions suggest that the desired conditions failed to occur. The school in question is a private institution whose fees are above the average income of the neighborhood in which it is located. This is yet another factor restricting TD children's ability to attend classes. Another limiting factor is the fact that one of the observers analyzing the reliability data was the school's vice principal. Since she was aware of the study's objectives, her presence is thought to have possibly affected the reliability data. However, the similarity between her observations with those of the second observer, who did not witness the practices in their own setting. 
As a result of the study's findings, the following suggestion has been made: Conditions for opening and administrating reverse mainstreaming classes and schools should be publically mandated so as to ensure their success. Conditions to be incorporated include the presence of two teachers in the classroom, both a preschool education teacher and a special education teacher; the percentage of TD and SN children should be 2 to 1 ; financial and other incentives should be offered to families of TD children so as to ensure their attendance to these classes.

Suggestions for future research include repeating this study in general education classes with VI children who have attended preschool classes less. Other topics worthy of research include teaching VI children social interaction skills, how and when to apply the skills that they have learned, how to effectively and efficiently inform their TD peers that they have a visual impairment, and how well both

\section{References}

Alberto, P. A., \& Troutman, A. C. (2009). Applied behavior analysis for teachers (8th ed.). Upper Saddle River, NJ: Pearson Education.

Bishop, M., Hobson, R. P., \& Lee, A. (2005). Symbolic play in congenitally blind children. Development and Psychopathology, 17(2), 447-465.

Brambring, M. (2001). Integration of children with visual impairment in regular preschools. Child: Care, Health and Development, 27(5), 425-438.

Brown, R., Hobson, R. P., Lee, A., \& Stevenson, J. (1997). Are there "Autistic-like" features in congenitally blind children? Journal of Child Psychology and Psychiatry, 38(6), 693-703.

Cass, H. D., Sonksen P. M., \& McConachie H. R. (1994). Developmental setback in severe visual impairment. Archives of Disease in Childhood, 70, 192-196.

Celeste, M. (2006). Play behaviors and social interactions of a child who is blind: In theory and practice. Journal for Visual Impairment and Blindness, 100(2), 75-90.

Celeste, M. (2007). Social skills intervention for a child who is blind. Journal of Visual Impairment and Blindness, 101(9), 521-533.

Celeste, M., \& Grum, D. K. (2010). Social integration of children with visual impairment: A developmental model. Elementary Education Online, 9(1), 11-22.

Crocker, A. D., \& Orr, R. R. (1996). Social behaviors of children with visual impairments enrolled in preschool programs. Exceptional Children, 62, 451-461.

D'Allura, T. (2002). Enhancing the social interaction skills of preschoolers with visual impairments. Journal of Visual Impairment and Blindness, 96(8), 576-584.
TD and VI children use social interaction skills in the same class. In addition, whether or not children generalize the social activities that they have learned to other activities, such as outdoor play activities, art events, and dining skills, can also be investigated. Since allowing VI children to acquire social skills is not only essential to make independent decisions, taking responsibility for one's own actions, and feeling successful and secure in the world, but also for their classroom peers to accepted them, the applicability and effectiveness of teaching VI children the play skills taught in this study in minimizing repetitive behaviors can also be investigated.. In particular, the applicability and effectiveness of the on the job training model to be applied to preschool teachers on the social interaction skills of $\mathrm{SN}$ children in mainstreaming classes can also be investigated. In addition, future researchers can examine the effectiveness of grandparents in teaching early play skills to VI children.
Dale, N., \& Sonksen, P. (2002). Developmental outcome, including setback, in young children with severe visual impairment. Developmental Medicine and Child Neurology, 44(9), 613-622.

English, K., Goldstein, H., Shafer, K., \& Kaczmarek, L. (1997). Promoting interactions among preschoolers with and without disabilities: Effects of a buddy skills- training program. Exceptional Children, 63(2), 229-243.

Erwin, E. J. (1993). Social participation of young children with visual impairments in specialized and integrated environments. Journal of Visual Impairment and Blindness, 87(5), 138-142.

Fabes, R. A., Hanish, L. D., \& Martin, C. L. (2003). Children at play: The role of peers in understanding the effects of child care. Child Development, 74(4), 1039-1043.

Fantuzzo, J., Sutton-Smith, B., Coolahan, K. C., Manz, P. H., Canning, S., \& Debnam, D. (1995). Assessment of preschool play interaction behaviors in young low-income children: Pen interactive peer play scale. Early Childhood Research Quarterly, 10(1), 105-120. doi:10.1016/08852006(95)90028-4

Ferguson, R., \& Buultjens, M. (1995). The play behaviour of young blind children and its relationship to developmental stages. British Journal of Visual Impairment, 13(3), 100107.

Fewell, R. R., \& Sandall, S. R. (1983). Curricula adaptations for young children: Visually impaired, hearing impaired, and physically impaired. Topics in Early Childhood Special Education, 2(4), 51-66. doi:10.1177/027112148300200411

Giangreco, M. F., Edelman, S. W., Luiselli, T. E., \& Macfarland, S. Z. C. (1997). Helping or hovering? Effects of instructional assistant proximity on students with disabilities. Exceptional Children, 64(1), 7-18. 
Gök, G., \& Erbaş, D. (2011). Okul öncesi eğitimi öğretmenlerinin kaynaştırma eğitimine ilişkin görüșleri ve önerileri. International Journal of Early Childhood Special Education, 3(1), 66-87.

Goldstein, H., \& Ferrell, D.R. (1987). Augmenting communicative interaction between handicapped and nonhandicapped preschool children. Journal of Speech and Hearing Disorders, 52, 200-211.

Goldstein, H., \& Wickstrom, S. (1986). Peer intervention effects on communicative interaction among handicapped and nonhandicapped preschoolers. Journal of Applied Behavior Analysis, 19(2), 209-214.

Goldstein, H., Kaczmarek, L., Pennington, R., \& Shafer, K. (1992). Peer-mediated intervention: Attending to commenting on, and acknowledging the behavior of preschoolers with autism. Journal of Applied Behavior Analysis, 25(Summer), 289-305.

Gronna, S., Serna, L. A., Kennedy, C. H., \& Prater, M. A. (1999). Promoting generalized social interactions using sociodramatic scripts in an integrated preschool setting: A single-case study. Behavior Modification, 23, 419-440.

Guralnick, M. J. (1997). The peer social networks of young boys with developmental delays. American Journal on Mental Retardation, 101(6), 595-612.

Guralnick, M. J. (1999). The nature and meaning of social integration for young children with mild developmental delays in inclusive settings. Journal of Early Intervention, 22(1), 70-86.

Guralnick, M. J. (2010). Early intervention approaches to enhance the peer-related social competence of young children with developmental delays. Infants and Young Children, 23(2), 73-83.

Guralnick, M. J., Neville, B., Hammond, M. A., \& Connor, R. T. (2007). The friendships of young children with developmental delays: A longitudinal analysis. Journal of Applied Developmental Psychology, 28, 64-79.

Hobson, R. P., \& Lee, A. (2010). Reversible autism among congenitally blind children? A controlled follow-up study. Journal of Child Psychology and Psychiatry, 51(11), 11851295.

James, D., \& Stojanovik, V. (2007). Communication skills in blind children: A preliminary investigation. Child: Care, Health and Development, 33(1), 4-10.

Kratochwill, T. R., Hitchcock, J., Horner, R. H., Levin, J. R., Odom, S. L., Rindskopf, D. M., \& Shadish, W. R. (2010). Single-case designs technical documentation. Retrieved from http://ies.ed.gov/ncee/wwc/pdf/wwc_scd.pdf

Laushey, K. M., \& Heflin, L. J. (2000). Enhancing social skills of kindergarten children with Autism through the training of multiple peers as tutors. Journal of Autism and Developmental Disorders, 30(3), 183-193.

Laushey, K. M., Heflin, L. J., Shippen, M., Alberto, P. A., \& Fredrick, L. (2009). Concept mastery routines to teach social skills to elementary children with high functioning autism. Journal of Autism and Developmental Disorders, 39(10), 1435-1448. doi:10.1007/s10803-009-0757-9

Macy, M., Squires, J. K., \& Barton, E. E. (2009). Providing optimal opportunities. Topics in Early Childhood Special Education, 28(4), 209-218.

McGaha, C. G., \& Farran, D. C. (2001). Interaction in an inclusive classroom. Journal of Visual Impairment and Blindness, 95, 80-95.

McGinnis, E., \& Goldstein, A. P. (2003). Skill streaming in early childhood - program forms (rev. ed.) Illinois, IL: Research Press.
McWilliam, R. A., \& Casey, A. M. (2008). Engagement of every child in the preschool classroom. Baltimore, MD: Paul $\mathrm{H}$. Brookes Publishing.

Mukaddes, N. M., Kılınçaslan, A., Küçükyazıcı, G., Şevketoğlu, T., \& Tuncer, S. (2007). Autism in visually impaired individuals. Psychiatry and Clinical Neurosciences, $61,39-44$.

Odom, S. L., \& McEvoy, M. A. (1990). Mainstreaming at the preschool level: Potential barriers and tasks for the field. Topics in Early Childhood Special Education, 10(2), 48-61.

Odom, S. L., \& Ogawa, I. (1992). Direct observation of young children's social interaction with peers: A review of methodology. Behavioral Assessment, 14, 407-441.

Odom, S. L., \& Strain, P. S. (1984). Peer-mediated approaches to promoting children's social interaction: A review. American Journal of Orthopsychiatry, 54(4), 544557.

Odom, S. L., \& Watts, E. (1991). Reducing teacher prompts in peer-mediated interventions for young children with autism. The Journal of Special Education, 25(1), 26-43.

Özaydın, L., \& Çolak, A. (2011). Okul öncesi öğretmenlerinin "kaynaştırma eğitimine" ve "okul öncesi eğitimde kaynaştırma eğitimi hizmet içi eğitim programı" na ilişkin görüşleri. Kalem Eğitim ve İnsan Bilimleri Dergisi, 1(1), 189-226.

Özaydın, L., Tekin-İftar, E., \& Kaner, S. (2008). Arkadaşlık becerilerini geliștirme programının özel gereksinimi olan okul öncesi çocuklarının sosyal etkileşimlerine etkisi. Özel Eğitim Dergisi, 9(1), 15-32.

Piaget, J. (1970). Genetic epistemology. New York, NY: Columbia University Press.

Pizzo, L., \& Bruce, S. B. (2010). Language and play in students with multiple disabilities and visual impairments or deaf-blindness. Journal of Visual Impairment and Blindness, 104(5), 287-297.

Preisler, G. (1993). A descriptive study of blind children in nurseries with sighted children. Child: Care, Health and Development, 19(5), 295-315.

Rakap, S. (2015). Effect sizes as result interpretation aids in single-subject experimental research: Description and application of four nonoverlap methods. British Journal of Special Education, 42(1), 11-33.

Rogers, S. J., \& Puchalski, C. B. (1984). Development of symbolic play in visually impaired young children. Topics in Early Childhood Special Education, 3(4), 57-63.

Sainato, D. M., Goldstein, H., \& Strain, P. S. (1992). Effects of self evaluation on preschool children's use of social interaction strategies with their classmates with autism. Journal of Applied Behavior Analysis, 25(1), 127-141.

Strain, P. S., \& Odom, S. L. (1986). Peer social initiations: Effective intervention for social skills development of exceptional children. Exceptional Children, 52(6), 543-551.

Tait, P. E., \& Wolfgang, C. (1984). Mainstreaming a blind child - Problems perceived in a preschool day care program. Early Child Development and Care, 13(2), 155-167.

Tekin İftar, E., Kurt, O., \& Çetin, Ö. (2011). Yüksek ve düşük uygulama güvenirliğiyle sunulan sabit bekleme süreli öğretim uygulamalarının karşılaştırılması. Kuram ve Uygulamada Eğitim Bilimleri, 11(1), 363-381.

Tekin-İftar, E., \& Kurcaali İftar, G. (2006). Özel eğitimde yanlışıı öğretim yöntemleri. Ankara: Nobel Yayın Dağıtım.

Terpstra, J. E., \& Tamura, R. (2008). Effective social interaction strategies for inclusive settings. Early Childhood Education Journal, 35, 405-441. 
Tröster, H., \& Brambring, M. (1994). The play behaviour and play materials in blind and sighted infants and preschoolers. Journal of Visual Impairment and Blindness, 88(4), 421-432.

Tröster, H., Brambring, M., \& Beelmann, A. (1991). Prevalence and situational causes of stereo-typed behavior in blind infants and preschoolers. Journal of Abnormal Child Psychology, 19(5), 569-590.
Wall, R. (2002). Teachers' exposure to people with visual impairments and the effect on attitudes toward inclusion. RE:view, 34(3), 111-119.

Wolery, M., \& Wilbers, J. S. (1994). Including children with special needs in early childhood programs. Washington DC., MD: National Association for the Education of Young Children. 